\title{
MMP13 is potentially a new tumor marker for breast cancer diagnosis
}

\author{
HUI-JEN CHANG ${ }^{1,2 *}$, MING-JE YANG ${ }^{3 *}$, YU-HSIANG YANG ${ }^{2}$, MING-FENG HOU ${ }^{4,5}$, \\ ER-JUNG HSUEH ${ }^{6,7}$ and SHIU-RU LIN ${ }^{1,2}$ \\ ${ }^{1}$ School of Medical and Health Science, Fooyin University, ${ }^{2}$ Department of Medical Research, Fooyin University Hospital, \\ ${ }^{3}$ Graduate Institute of Medicine, Kaohsiung University, ${ }^{4}$ Faculty of Biomedical Science and Environmental Biology, \\ Kaohsiung Medical University, ${ }^{5}$ Division of Gastrointestinal and General Surgery, Department of Surgery, \\ Kaohsiung Medical University Hospital, ${ }^{6}$ Division of Oncology and Hematology, Pingtung Christian Hospital, \\ ${ }^{7}$ Department of Internal Medicine, Pingtung Christian Hospital, Taiwan, R.O.C.
}

Received March 3, 2009; Accepted April 23, 2009

DOI: 10.3892/or_00000544

\begin{abstract}
Within the past decade, the incidence of breast cancer in Taiwan has been rising year after year. Breast cancer is the first most prevalent cancer and the fourth leading cause of cancer-related deaths among women in Taiwan. The early stage of breast cancer not only have a wider range of therapeutic options, but also obtain a higher success rate of therapy than those with advanced breast cancer. A test for tumor markers is the most convenient method to screen for breast cancer. However, the tumor markers currently available for breast cancer detection include carcinoembryonic antigen (CEA), carbohydrate antigen 15.3 (CA15.3), and carbohydrate antigen 27.29 (CA27.29) exhibited certain limitations. Poor sensitivity and specificity greatly limits the diagnostic accuracy of these markers. This study aims to identify potential tumor markers for breast cancer. At first, we analyzed genes expression in infiltrating lobular carcinoma, metaplastic carcinoma, and infiltrating ductal carcinoma of paired specimens (tumor and normal tissue) from breast cancer patients using microarray technology. We selected 371 overexpressed genes in all of the three cell type. In advanced breast cancer tissue, we detected four genes MMP13, CAMP,
\end{abstract}

Correspondence to: Dr Shiu-Ru Lin or Dr Er-Jung Hsueh, Bio-medical Technology Developmental Center, Fooyin University, No. 151 Jinsyue Road, Daliao Township, Kaohsiung County, 831 Taiwan, R.O.C.

E-mail:do004@mail.fy.edu.tw; erjunghsueh@gmail.com

${ }^{*}$ Contributed equally

Abbreviations: MMP13, matrix metallopeptidase 13; CEA, carcinoembryonic antigen; CA, carbohydrate antigen; CAMP, cathelicidin antimicrobial peptide; COR10A1, collagen, type X, $\alpha$ 1; FCJ25416, chromosome 11 open reading frame 82

Key words: MMP13, tumor marker, breast cancer
COL10A1 and FLJ25416 from 25 overexpressed genes which encoded secretion protein more specifically for breast cancer than other genes. After validation with 15 pairs of breast cancer tissue and paired to normal adjacent tissues by membrane array and quantitative RT-PCR, we found MMP13 was $100 \%$ overexpressed and confirmed to be a secreted protein by Western blot analysis of the cell culture medium. The expression level of MMP13 was also measured by immunohistochemical staining. We suggest that MMP13 is a highly overexpressed secretion protein in breast cancer tissue. It has potential to be a new tumor marker for breast cancer diagnosis.

\section{Introduction}

New cases $(910,000)$ of breast cancer appear globally every year, and 376,000 people die as a result (1). In 2006, breast cancer is estimated to account for $31 \%$ new onset female cancers (2). In Taiwan, breast cancer has the highest incidence among all female cancers (3) and is ranked fourth in all cancer deaths (4). In the Taiwanese breast cancer patients the first occurrence of this disease is often at a young age. According to statistics, more than $50 \%$ of total breast cancer diagnosed annually in Taiwan derives from patients under 50 years old, and this proportion is higher than that observed in Western population $(5,6)$.

Early diagnosis of breast cancer can provide patients a wider range of therapeutic options as well as a higher success rate of therapy that lowers mortality. Through proper treatment, the 10 -year survival rate can reach $60 \%$, and the stage I survival rate can be as high as $80 \%$. Survival rate in stage 0 is close to $100 \%$ (7). These data indicate that early diagnosis and treatment of breast cancer is the key to higher survival rates.

Currently, mammography, MRI (magnetic resonance imaging), and tumor markers are the most commonly used diagnostic tools for breast cancer but they have inherent limitations. Mammography is widely used as a convenient screening tool in women over 50 years, but it does not have high sensitivity. Therefore, $<50 \%$ of patients are diagnosed 
through mammography (8). Mammography is also limited by refined breast tissues. Younger women in Taiwan have more refined breast cancer tissues, which can affect sensitivity, but the tumors in these patients are usually more invasive (9).

Tumor markers could become the most convenient method for clinic breast cancer diagnosis in the future, and they do not cause any side effects. Presently, the ones used for breast cancer include: CEA (carcinoembryonic antigen), CA15.3 (Carbohydrate antigen15.3), and CA 27,29 (Carbohydrate antigen 27,29$)(10)$. However, these markers have a low sensitivity and specificity in breast cancer diagnosis, thereby diminishing their accuracy. Clinical practice guidelines from the American Society of Clinical Oncology (ASCO) warn against the use of CA15.3 or CEA diagnoses for breast cancer $(11,12)$. They are only recommended as therapeutic monitors for late-stage breast cancer and recurrences (13). Thus, in clinical diagnosis, more sensitive and more specific tumor markers are needed.

This laboratory utilizes the complete and highly efficient gene screening technology of microarray to analyze the gene expression of breast cancer and normal tissues. From these tests we were seeking genes with high expression of breast cancer that may serve as a tumor marker. Therefore, we used three pairs of normal and breast cancer tissue samples of different cell types (infiltrating lobular carcinoma, metaplastic carcinoma, and infiltrating ductal carcinoma) and performed microarray analysis using the Agilent Oligo array. As a result, 371 genes with expression levels in tumor tissue 2-fold higher than normal tissue in all three cell type groups were selected. We discovered 25 genes which encode secretion protein from 371 genes by employing bioinformatics studies. Of the 25 genes, MMP13, CAMP, COL10A1, and FLJ25416 are more specific for breast cancer than other genes. We utilized membrane array and RT-PCR in 15 pairs of tissues of clinical cancer patients, and proved that MMP13 was the most commonly overexpressed gene among the 4 markers in breast cancer patients. We employed cell culture and performed Western blot analysis, proving that MMP13 is a secretion protein. Finally, using immunohistochemical (IHC) staining, we proved that MMP13 was highly overexpressed in the breast tissue of general breast cancer patients $(100 \%)$. Results from this study demonstrated that MMP13 is a potential new tumor marker for breast cancer.

\section{Materials and methods}

Clinical tissue sample collection. All paired samples including tumor and tumor-free tissues were obtained by clinical pathologist from 45 patients diagnosed of breast cancer at Chung-Ho Memorial Hospital of Kaohsiung Medical University during 2003-2007. Tumor grading was carried out and confirmed by pathologists. Samples were further used for microarray analysis, establish primary culture cell lines, real-time PCR and membrane array analysis.

Oligonucleotide microarray. The oligonucleotide array contains 22,500 elements designed for expression profiling (Human 1A V2, Agilent Technologies, Palo Alto, CA, USA), for which over 18,000 well-characterized, full-length human genes were defined. First-strand cDNA targets for hybri- dization were made by reverse transcription of the mRNA isolated from both the tumor and paired normal tissues from the same case by using SuperScript II RT (Gibco-BRL, Gaithersburg, MD, USA) in the presence of either Cy3or Cy5-labeled dUTP (Amershan Pharmacia Biotech, Piscataway, NJ, USA). The targets were dried to $18 \mu 1$ by a SpeedVac ${ }^{\mathrm{TM}}$ concentrator (Thermo Electron Co., Waltham, MA, USA), and $3.6 \mu 120 X \mathrm{SSC}, 1.8 \mu 110 \mathrm{mg} / \mathrm{ml}$ poly-A and $0.54 \mu 110 \%$ SDS were added. Then, the mixture was heated to $100^{\circ} \mathrm{C}$ for 2 min proceeding to hybridization reaction on Human 1A Oligo Microarray V2 array slides (Agilent Technologies) in an incubator at $63^{\circ} \mathrm{C}$ for $12-16 \mathrm{~h}$. After being sequentially washed with $1 \mathrm{X} \mathrm{SSC,} 0.2 \mathrm{X}$ SSC and $0.05 \mathrm{X}$ SSC, hybridized microarray slides were scanned and fluorescence signals were detected by using an Axon GenePix 4000A dual-color confocal laser scanner (Axon Instruments, Union, CA, USA). Subsequent quantification analysis was performed using the commercial software GenePix Pro 3.0 $0^{\mathrm{TM}}$ (Axon Instruments). The acceptance criterion for a gene signal was a signal-to-noise ratio of $\geq 2$. If either the Cy3 or Cy5 signal of a specific spot passed the criterion, the flag of its ratio was counted to be 'TRUE'. The elements with the 'TRUE' flag were analyzed with GeneSpring GX7 (Slilicon Genetics, Redwood, CA, USA). The differentially expressed elements were analyzed by the two-sided statistical tolerance interval $(95 \%)$.

Predicting secretion protein. We used three types of breast cancer and paired them with the corresponding normal tissues to perform three microarray technology studies. After analysis with GeneSpring Biological data analysis software, we found that 371 genes were overexpressed 2-fold or more in the three groups of breast cancer tissues. The overexpressed gene groups of the breast tumors were further analyzed with Swiss-Prot, Secreted protein database (SPD) (14), Signal P3.0 (15), and pTARGET (16) to predict and screen for the ones that were secretion proteins. The selected ones represent breast cancer tumor marker candidate genes.

Virtual Northern analysis. The functions of Cancer Genome Anatomy Project (CGAP) of National Center for Biotechnology Information (NCBI), genetic information of the breast cancer tumor marker candidate genes, such as EST data and SAGE data, were used as adjunctive confirmation, to further select the ones with the most specificity for breast cancer.

Total RNA extraction and first strand cDNA synthesis. Total RNAs were extracted from breast cancer patient's tissue and cell line with ISOGEN ${ }^{\mathrm{TM}}$ (Nippon Gene, Toyama, Japan) and QIAmp ${ }^{\circledR}$ RNA Blood Mini Kit (Qiagen Inc., Valencia, CA) according to the manufacturer's instructions (17). The RNA concentration was determined spectrophotometrically on the basis of absorbance at $260 \mathrm{~nm}$ (Beckman, DU800, and USA). First strand cDNA was synthesized from total RNA by using a RT-PCR kit (Promega Co., Madison, WI). The reverse transcription was carried out in a reaction mixture consisting of $1 \mathrm{X}$ Transcription Optimized 5X Buffer, $25 \mu \mathrm{g} / \mathrm{ml}$ oligo (dT)-15mer primer, $100 \mathrm{mmol} / \mathrm{l}$ PCR Nucleotide Mix, $200 \mu \mathrm{mol} / \mathrm{l}$ M-MLV Reverse Transcriptase, and $25 \mu \mathrm{l}$ of 
Table I. Primer sequences of target genes.

\begin{tabular}{lll}
\hline Gene & \multicolumn{1}{c}{ Sequence } & Product (bp) \\
\hline CAMP & $\begin{array}{l}\text { Forward 5'-CAGCAGGGCAAATCTCTTGTTATCCT-3' } \\
\text { Reverse 5'-CTACCGCCTCCTGGACCTGGA-3' }\end{array}$ & 241 \\
COL10A1 & Forward 5'-CTTCACTTGAATGGGAGGCACAAGG-3' \\
MMP13 & Reverse 5'-TGCAAGGTGCTTTCATCAATGAACC-3' \\
& Forward 5'-GTTCTTCCCTTGATGGCCGATCATAT-3' \\
FLJ25416 & Reverse 5'-GTGATCCCTTGAGATATGGAAGGATGC-3' \\
& Forward 5'-GCTCCCAGCAGAGTCCTGTTTTCAAT-3' \\
ß-actin ${ }^{\mathrm{a}}$ & Reverse 5'-AGGCCCACCTTCAGTGTGTGAAACT-3' & 228 \\
& Forward 5'-GCATCCACGAAACTACCTTC-3' & 190 \\
\hline
\end{tabular}

${ }^{\mathrm{a}} \mathrm{B}$-actin primers were added as internal controls to correct for the differences in different cells.

Table II. Oligonucleotide sequences of target genes.

\begin{tabular}{lc}
\hline Gene name & Oligonucleotide sequence \\
\hline COL10A1 & 5'-AGATATTGATGAAAGGGGCCATACAGGCCTCAGAGTAGTGCACCATCAGA-3' \\
CAMP & 5'-TCTATAGCACGAAGCACAGCTTCCTTGTAGCTGAGGACCTGGGCAATGAT-3' \\
MMP13 & 5'-AATAAGTGCCAAGCACCCTCCCCAAGTATCAATAGGCACTGTGGGAAGTG-3' \\
FLJ25416 & 5'-TGACTTCTGAACAAGAATCAGGTCCAAGAATAGGGTGCAGCTGAGGTGCT-3' \\
\hline
\end{tabular}

Recombinant RNasin ${ }^{\circledR}$ Ribonuclease Inhibitor (Promega). The reaction mixtures with RNA were incubated at $42^{\circ} \mathrm{C}$ for longer than $2 \mathrm{~h}$, heated to $95^{\circ} \mathrm{C}$ for $5 \mathrm{~min}$, and then stored at $-80^{\circ} \mathrm{C}$ until analysis.

Real-time polymerase chain reaction (RT-PCR). Two microliters of each cDNA sample were used for each reaction. Sequences of the oligonucleotide primers (Table I) were designed according a PCR primer selection program based on primer 3 at http://frodo.wi.mit.edu/cgi-bin/primer3/prime 3 www.cgi. Each RT-PCR reaction mixture contained $1 \mathrm{X}$ PCR buffer (10 mmol/l Tris-HCl, pH 8.3, $50 \mathrm{mmol} / 1 \mathrm{KCl}, 2$ $\mathrm{mmol} / 1 \mathrm{MgCl}_{2}$ ), $50 \mu \mathrm{mol} / 1 \mathrm{dNTP}, 0.1 \mu \mathrm{mol} / 1$ sense and antisense primers for target genes, and $0.01 \mu \mathrm{mol} / 1$ sense and antisense primers for $\beta$-actin. PCR products were analyzed in $3 \%$ agarose gel containing $0.5 \mu \mathrm{g} / \mathrm{ml}$ ethidium bromide. The signals on UV transilluminator for each target gene and $B$-actin expression levels were scanned with a computing laser densitometer (Alpha Inotech, San-Leandro, CA) to calculate the relative mRNA density. Real-time PCR was performed in a Rotor-Gene 2000 thermocycler (Corbett Research, Inc.). The reaction mixture contained $2 \mu 1$ of $20 \mathrm{mM}$ dNTP, $2 \mu 1$ of $30 \mathrm{mM} \mathrm{MgCl}, 2 \mu \mathrm{l}$ of $20 \mathrm{X}$ SYBR-Green, $2 \mu \mathrm{l}$ of $1 \mu \mathrm{M}$ forward primer, $2 \mu \mathrm{l}$ of $1 \mu \mathrm{M}$ reverse primer, $4 \mu \mathrm{l}$ of nuclease free water, $2 \mu \mathrm{l}$ of $80-100 \mathrm{ng} / \mathrm{ml} \mathrm{cDNA}$, and $2 \mu \mathrm{l}$ of $1 \mathrm{U} / \mu 1$ polymerase. PCR conditions were as follows: 35 cycles of denaturation at $95^{\circ} \mathrm{C}$ for $20 \mathrm{sec}$, annealing at $60^{\circ} \mathrm{C}$ for $20 \mathrm{sec}$, and extension at $74^{\circ} \mathrm{C}$ for $40 \mathrm{sec}$. PCR products (i.e. synthesized dsDNA) were quantified by measuring the fluorescent intensity at the end of each amplification cycle. For each sample, real-time PCR analysis was repeated in three independent experiments to ensure the reproducibility of results. We used $\beta$-actin and Oryza sativa sequence as positive and negative controls, and DDwater as blank control.

Membrane array. The procedure of the membrane-array method for the detection of multiple genes simultaneously was performed based on our previous work (18-20). Visual OMP3 (Oligonucleotide Modeling Platform, DNA Software, Ann Arbor, MI) was used to design probes for each target gene and $B$-actin, and the latter served as an internal control (Table II). The probe selection criteria included strong mismatch discrimination, minimal or no secondary structure, the signal strength at the assay temperature, and lack of cross-hybridization. The oligonucleotide probes were then synthesized according to the designed sequences, purified, and controlled before being grafted onto the subtracts. The newly synthesized oligonucleotide fragments were dissolved in distilled water to a concentration of $20 \mathrm{mM}$, applied to a BioJet Plus $3000 \mathrm{nl}$ dispensing system (BioDot, Irvine, CA), which blotted the four target oligonucleotides, and the B-actin 
(A)

\begin{tabular}{|l|l|l|l|l|l|l|}
\hline COL10A1 & CAMP & MMP13 & FLJ25416 & negative & $\beta$-Actin & Blank \\
\hline COL10A1 & CAMP & MMP13 & FLJ25416 & negative & $\beta$-Actin & Blank \\
\hline COL10A1 & CAMP & MMP13 & FLJ25416 & negative & $\beta$-Actin & Blank \\
\hline
\end{tabular}

(B)

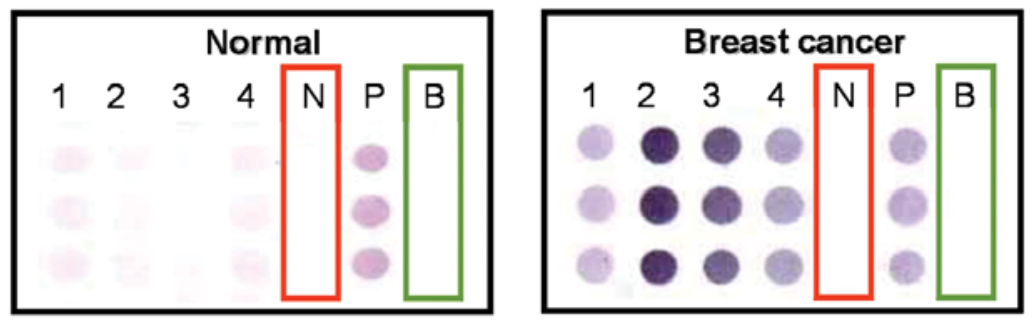

Figure 1. (A) Location of dotting on gene array nylon membranes: the arrangement of gene dotting on the nylon membranes is demonstrated. Each tested gene was dotted three times on the nylon membrane. On the right side, three repeated dots of negative control (TB, tuberculosis gene); three repeated dots of positive control (B-actin) and three repeated dots of blanks (50\% DMSO). N was negative control (blue box); P was positive control (red box) and B was blank (green box). (B) Color expression of Nylon membrane gene array: color effects of the four target genes on nylon membranes. The tissue samples are breast cancer tissue paired with normal breast tissue. Left panel, the genetic expression of a normal breast tissue sample. Right panel, the genetic expression of a breast cancer tissue sample. The three dots in column 1 belongs to COL10A1; column 2, CAMP; column 3, MMP13; column 4, FLJ25416.

control sequentially $(0.05 \mu \mathrm{l}$ per spot and $1.5 \mathrm{~mm}$ between spots) on SuPerCharge nylon membrane (Schleicher and Schuell, Dassel, Germany) in triplicate. Dimethyl sulfoxide (DMSO) was also dispensed onto the membrane as a blank control (Fig. 1A). After rapid drying and cross-linking procedures, the preparation of hypoxia- and glycolysis-associated gene expression membrane array was accomplished (21).

Preparation of digoxigenin (DIG)-labeled cDNA targets and hybridization. First-strand cDNA targets for hybridization were made by reverse transcription of the mRNA from the tumor and corresponding normal tissues of breast cancer patients in the presence of DIG-labeled UTP (Roche Diagnostics GmbH, Penzberg, Germany) using SuperScript II reverse transcriptase (Gibco-BRL). The membrane array needs prehybridization at $42^{\circ} \mathrm{C}$ for $2 \mathrm{~h}$ in a hybridization oven (Autoblot Bellco, Vineland, NJ, USA), and subsequent blocking before hybridization. The lifts were covered with the ExpressHyb Hybridization Solution (BD Biosciences, Palo Alto, CA, USA) containing DIG-11-UTPlabeled cDNA probes, and then incubated with an anti-DIG alkaline phosphatase conjugated antibody (Roche Diagnostics) at a dilution of 1:2500 $(75 \mathrm{mU} / \mathrm{ml})$ in 1X blocking buffer (100 mM Maleic acid, $150 \mathrm{mM} \mathrm{NaCl}, \mathrm{pH} 7.5)$. We incubated the arrays for hybridization at $42^{\circ} \mathrm{C}$ overnight in a humid shaking chamber. After washing each one three times for $10 \mathrm{~min}$ in $20 \mathrm{ml}$ washing buffer, the arrays were exposed to excitation light. For signal detection, the membranes we incubated for 15 min without shaking in a chromogen solution containing nitroblue-tetrazolium and 5-bromo-4-chloro3-indolylphosphate (NBT/BCIP).

Statistical analysis of membrane array. All data were analyzed using the Statistical Package for the Social Sciences Version
11.5 software (SPSS Inc., Chicago, IL). Data are presented as means $\pm \mathrm{SE}$ and P-values were determined by unpaired Student's t-test. Furthermore, the two-sided Pearson $\chi^{2}$ test was used to analyze the differences in the overexpression of the genotypes between different age groups, gender and stages. A P-value of $<0.05$ was considered statistically significant.

ATCC cell lines. Five different kinds of cell lines were purchased from ATCC (American Type Culture Collection, ATCC, Rockville, MD, USA) including four human breast cancer cell lines [ZR-75-1(CRL-1500), MDA-MB-231 (HTB-26), T-47D(HTB-133) and MCF-7(HTB-22)], two human colorectal cancer cell lines [CCL-228(SW480) and CCL-227(SW620)], one normal human cell line [CRL-9609 (BEAS-2B)], two human lung cancer cell lines [CRL-5800 (NCI-H23) and CRL-5807(NCI-H358)] and one human cervical cancer cell line [CRL-13011(HeLa NR1)]. ZR-75-1 (CRL-1500), T-47D(HTB-133), MCF-7(HTB-22), CRL9609(BEAS-2B), CRL-5800(NCI-H23), CRL-5807(NCIH358) and CRL-13011(HeLa NR1) cell lines were cultured with RPMI-1640, 10\% FBS, 1.5 gl sodium bicarbonate, $10 \mathrm{mM}$ HEPES, $1.0 \mathrm{mM}$ sodium pyruvate and $1 \%$ antibiotic-antimycotic cell cultivating solution at $37^{\circ} \mathrm{C}$ and $5 \%$ $\mathrm{CO}_{2}$; MDA-MB-231(HTB-26), CCL-228(SW480), CCL-227 (SW620) was cultured with Leibovitz's L-15 medium, 10\% FBS, and $1 \%$ antibiotic-antimycotic of cell cultivating solution at $37^{\circ} \mathrm{C}$ and $100 \%$ air.

Establishment of primary culture cell lines. Fresh samples collected from the operating room were immersed in $50 \mathrm{ml}$ of phosphate-buffered saline (PBS), in a centrifuge tube and maintained at $4^{\circ} \mathrm{C}$, followed by transport to the laboratory for immediate cultivation. The time from the removal of sample from the patient in the operating room to the start of the 
cultivation process did not exceed $4 \mathrm{~h}$. Operational procedures referred to Freshney (23), mainly involving enzyme digestion and they were gradually adjusted based on process of the study and experience. After testing under different conditions, the following standard procedures were utilized in the study: $0.00625 \mathrm{~g}$ of collagenase (Sigma C9891) was dissolved in $12 \mathrm{ml}$ Hanks' balanced salt solution, then prepared through a $0.22 \mu \mathrm{m}$ filter. Sample tissues were first washed with PBS twice under the laminar flow hood, then placed into a 6-well culture plate and cut into pieces with a No.10 surgical blade. After cutting to a size of about $1 \mathrm{~mm}^{2}$, the tissues were washed with collagenase solution and transferred to a $50 \mathrm{ml}$ centrifuge tube, and placed in room temperature to react for 45-50 $\mathrm{min}$, depending on the size of the tissue sample. A 50-ml centrifuge was prepared and $10 \mathrm{ml}$ of RPMI-1640 and $10 \%$ FBS cell culture solution were added. After waiting 45-50 min for the collagenase to act, the solution was filtered through $0.5 \mathrm{~mm}$ of molecular pores into the prepared $10 \mathrm{ml}$ RPMI-1640, and 10\%FBS cell culture solution was added to stop the action of collagenase. The solution was then centrifuged at $1,000 \mathrm{rpm}$ for $10 \mathrm{~min}$. The clear solution on top was discarded, and then the RPMI1640 and $10 \%$ FBS cell culture solution was added to disperse the cells. Finally, cells were transferred to a T25 tissue culture flask. The flask was placed into a fixedtemperature $\mathrm{CO}_{2}$ incubator. The growth criteria for the cell line were $37^{\circ} \mathrm{C}, 5 \% \mathrm{CO}_{2}$, and $\mathrm{pH} 7.4$. This primary culture cell line displayed biological characteristics of slow growth, and the subculture required a significantly long time, which corresponded with the postulations of Fournier et al (22). To minimize the mixture of fibroblasts during cell line cultivation, we employed different speeds in cell adherence to gradually reduce the amount of fibroblasts (23). Fibroblasts have the characteristic of rapid adherence (after subculture with pancreatin for $30 \mathrm{~min}$, adherence begins). Therefore, in each subculture process, the tissue culture flask was first placed in a $37^{\circ} \mathrm{C}, 5 \% \mathrm{CO}_{2}$ fixed temperature $\mathrm{CO}_{2}$ incubator for cultivation. Afterwards, the culture solution containing unadhered epithelial cells was transferred to a new tissue flask. This method significantly reduces the amount of fibroblasts.

Western blot analysis. Cells were placed in a T75 culture dish and grown to $80 \%$ confluence. Next, the cell culture solution was discarded, and the cells were washed three times with PBS. Afterwards, $8 \mathrm{ml}$ of FBS culture solution was added, and placed into a $5 \% \mathrm{CO}_{2}$ incubator at $37^{\circ} \mathrm{C}$ for cultivation. After $48 \mathrm{~h}$, the top clear solution was collected, and then concentrated with an Amicon Ultra-4 PLGC Centrifugal Filter Unit (Blossom Biotechnologies Inc., Taiwan). After concentration, the clear cell solution on top was immediately stored at $-70^{\circ} \mathrm{C}$. After $4 \mu 1$ of reducing dye was added into $20 \mu \mathrm{l}$ of the concentrated clear cell solution sample, it was poured onto a specifically made $10 \%$ SDS electrophoresis gel for electrophoresis. The electric current was $40 \mathrm{~A}$. After electrophoresis, $95 \mathrm{~V}$ was used to blot the protein on the gel onto nitrocellulose paper (NC paper). Skim-milk was used to fill the gaps in the NC paper. Target protein antibodies were added under room temperature and shaken for $1 \mathrm{~h}$ for specificity linking.
After washing off non-specific bound antibodies with PBS, secondary antibodies of the target HRP were added and shaken for $1 \mathrm{~h}$ for immune reactions. After washing off extra antibodies, the substrate, Immobilon Western Chemiluminescent HRP Substrate (Millipore, Mississauga, ON), was added to achieve color effects.

Immunohistochemical stain (IHC). The biopsy samples of breast cancer tissues were baked on slides at $60^{\circ} \mathrm{C}$ for $1 \mathrm{~h}$. Then, the biopsy samples were soaked in xylene for $10 \mathrm{~min}$, and repeated twice. Afterwards, it was immersed in $100 \%$ of absolute alcohol for $5 \mathrm{~min}$, and repeated twice. Then, it was soaked in 85 and $75 \%$ alcohol, respectively, for $5 \mathrm{~min}$ each and then in distilled water for 5 min each for removal of wax. De-waxed biopsy samples were soaked in $10 \mathrm{mM}$ of sodium citrate, and placed in a microwave for $5 \mathrm{~min}$. Three repeated antigen retrieval procedures were then performed. When the tissue slides were cooled to room temperature, $3 \%$ of $\mathrm{H}_{2} \mathrm{O}_{2}$ was used to remove intrinsic catalase. Afterwards, the slides were washed with distilled water followed by blocking serum (normal rabbit serum 20X) being dripped on it for $1 \mathrm{~h}$. Then, first antibody, secondary antibody of the target biotin, and Streptavidin-HRP (Dako, \#K0675) were added separately and allowed to act for $1 \mathrm{~h}$. After washing off the antibody at the end of the specific bond, DAB substrate was added $(20 \mathrm{ml}$ of $\mathrm{DAB}+1 \mathrm{ml}$ sub-strate buffer solution; Dako, \#K3468). The slides were observed at all times under the microscope to prevent over dyeing. Finally, they were washed with TBST for 5 min three times, and the nuclei were stained with hematoxylin, using $1 \% \mathrm{NH}_{3} \mathrm{OH}$. The final step to make it transparent included passing the slide through 75 , 85,95 and $100 \%$ alcohol at 3-min intervals each to remove water. After passing through xylene for 5 min for secondary transparency, filter paper was used to dry the tissue biopsy samples and covered with a coverslip.

\section{Results}

Microarray analysis of clinical breast cancer tissues pairs. We utilized three pairs of breast cancer and tumor-free tissues of different cell types (infiltrating lobular carcinoma, metaplastic carcinoma, and infiltrating ductal carcinoma). All results from the experiments underwent standardized analysis and validation. Then, we used biological data software, GeneSpring, hierarchical clustering was performed in the three experimental groups to initially assess gene expressions of all genes on the chip. After further analysis and validation, 371 genes displayed overexpression and potentially serving as biological markers in breast cancer.

Identification of candidate genes by bioinformatics. The 371 overexpressed genes validated in the breast tissues, were analyzed with biological software such as Swiss-Prot secreted protein database (SPD) (14), Signal p3.0 (15), and pTARGET (16), and results indicated that a total of 25 genes contained a structural sequence of secretion protein (Table III). Furthermore, with the use of Virtual Northern functional software from NCBI, the EST and SAGE data of the 25 candidate genes were assessed for each gene's expression in different cancerous tissues. The genes, MMP13, CAMP, COL10A1 and 
Table III. Screened candidate genes from 371 overexpressed gene groups.

\begin{tabular}{|c|c|}
\hline Official symbol & Description \\
\hline COL10A1 $1^{\mathrm{a}}$ & Homo sapiens COL10A1 gene for collagen ( $\alpha-1$ type $\mathrm{X})$ \\
\hline ESM1 & Endothelial cell-specific molecule 1 \\
\hline CAMPa & Cathelicidin antimicrobial peptide \\
\hline CST6 & Cystatin E/M \\
\hline VGF & VGF nerve growth factor inducible \\
\hline INHBA & Inhibin, $\beta \mathrm{A}$ \\
\hline VEGF & Vascular endothelial growth factor \\
\hline APOC2 & Apolipoprotein C-II \\
\hline PLA2G10 & Phospholipase A2, group X \\
\hline WISP1 & WNT1 inducible signaling pathway protein 1 \\
\hline TUFT1 & Tuftelin 1 \\
\hline G1P2 & ISG15 ubiquitin-like modifier \\
\hline MMP13 ${ }^{\mathrm{a}}$ & Matrix metalloproteinase 13 (collagenase 3 ) \\
\hline CXCL11 & Chemokine (C-X-C motif) ligand 11 \\
\hline APOC1 & Apolipoprotein C-I \\
\hline FLJ25416 & Hypothetical protein FLJ25416 \\
\hline F11 & Coagulation factor XI \\
\hline TFRC & Transferrin receptor (p90, CD71) \\
\hline MGC39558 & Hypothetical protein MGC39558 \\
\hline MMP12 & Matrix metalloproteinase 12 (macrophage elastase) \\
\hline CXCL10 & Chemokine (C-X-C motif) ligand 10 \\
\hline OSF-2 & Osteoblast specific factor 2 (fasciclin I-like) \\
\hline EDN2 & Endothelin 2 \\
\hline ADRM1 & Adhesion regulating molecule 1 \\
\hline DLEU1 & Deleted in lymphocytic leukemia, 1 \\
\hline
\end{tabular}

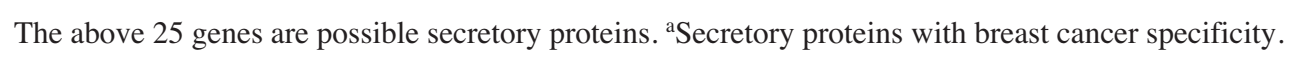

Table IV. Results of validation of target genes in paired clinical breast cancer tissue samples with real-time PCR and Nylon membrane gene array.

\begin{tabular}{lccr}
\hline Gene & $\begin{array}{c}\text { Positive result samples/total pare samples } \\
\text { (Real-time PCR) }\end{array}$ & $\begin{array}{c}\text { Positive result samples/total pare samples } \\
\text { (membrane array) }\end{array}$ & Positive rate (\%) \\
\hline COL10A1 & $12 / 15$ & $12 / 15$ & 80 \\
CAMP & $12 / 15$ & $12 / 15$ & 80 \\
MMP13 & $15 / 15$ & $15 / 15$ & 100 \\
FLJ25416 & $9 / 15$ & $9 / 15$ & 60 \\
\hline
\end{tabular}

FLJ25416 possessed the highest specificity for breast cancer. Therefore, these four genes were selected as the candidate target genes for this study.

Gene validation in clinical breast cancer tissues by membrane array and $R T-P C R$. To validate the expression of the abovementioned four genes in the breast tissue of clinical breast cancer patients, both membrane array and RT-PCR were conducted to detect the mRNA expression level from the 15 paired tissues. Based on results of membrane array hybridization analysis (Fig. 1B), if the gene presented a color response of $>2$-fold between the breast cancer and normal tissue, it was defined as overexpression. We found four genes with overexpression in breast cancer tissues (Table IV). MMP13 showed $100 \%$ overexpression in 15 breast cancer paired tissues, and was the highest among the four genes. The same finding was seen in RT-PCR. This indicated a high degree of consistency and correlation between the results of RT-PCR analysis and that of membrane array hybridization.

MMP13 protein was overexpressed in human breast cancer tissue. To further validate whether MMP13 is indeed a secretion protein, other than cultivating 4 lines of ATCC human breast cancer cell lines and 2 lines of primary culture cell lines of breast cancer, we also performed Western blot 


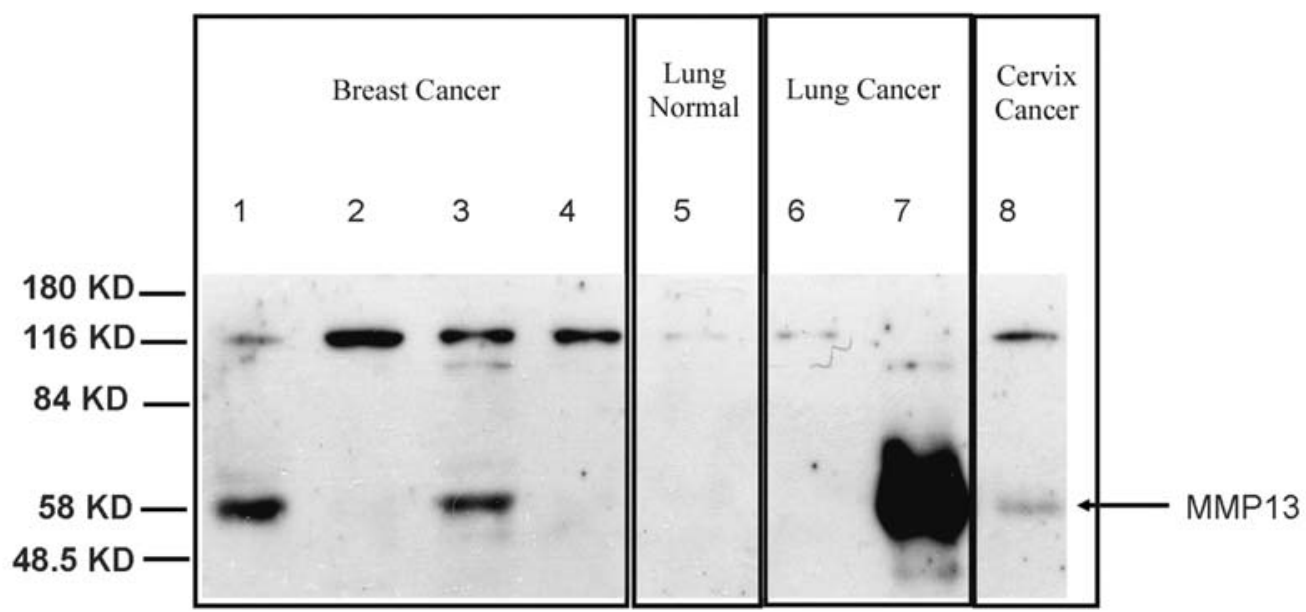

Figure 2. The top clear cell solution was collected and concentrated, and then Western blot analysis was used to confirm whether MMP13 is a secretory protein. Samples 1-4, ATCC human breast cancer cell line: 1, MDA-MB-231 cell line; 2, T-47D cell line; 3, ZR-75-1 cell line, and 4, MCF-7 cell line. Sample 5, normal ATCC human lung cell line CRL-9609. Samples 6 and 7, ATCC human lung cancer cell lines: 6, CRL-5800 cell line; 7, CRL-5807 cell line. Sample 8, ATCC human cervical cancer cell line CRL-13011.

Table V. Results of MMP13 secretion in 17 cell lines.

\begin{tabular}{llclc}
\hline Breast cancer & Colorectal cancer & Lung normal & Lung cancer & Cervical cancer \\
\hline HTB26(+) & SW480(+) & CRL9609 & CRL5800 & CRL13011(+) \\
HTB133 & SW620(+) & & CRL5807(+) & \\
CRL1500(+) & CP1 & & & \\
MCF7 & CP2 & & & \\
BP1(+) & CP3 & & & \\
BP2(+) & CP4(+) & & \\
& CP5 & $0 \%(0 / 1)$ & $50 \%(1 / 2)$ & $100 \%(1 / 1)$ \\
$66.67 \%(4 / 6)$ & $42.86 \%(3 / 7)$ & Th
\end{tabular}

+ indicates the cell line secretions expressed MMP13 protein. The percentage at the bottom of the table indicates positive rate, or expression of MMP13 in each cancer cell line. BP, breast cancer primary culture; CP, colon cancer primary culture.
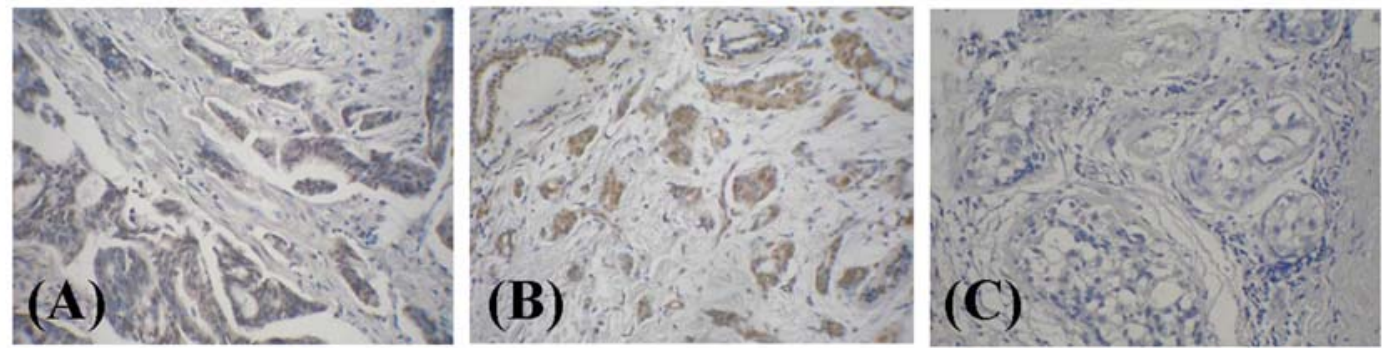

Figure 3. Using breast cancer tissue biopsy, immunohistochemical staining was performed with MMP13 antibody on these tissues, in order to investigate expression of MMP13 protein in breast cancer tissues. (A) and (B), breast cancer tissue biopsy samples with overexpression of MMP13. (C) a negative control with non-immune serum. All pictures magnification x200.

analysis for MMP13 protein detection in 2 lines of ATCC human colorectal cell lines, 2 ATCC human lung cancer cell lines, and 1 ATCC human cervical cancer cell line. MMP13 (pro form) and MMP13 (active form) protein of $60 \mathrm{kDa}$ of molecular weight were detected on the clear cell solution (Fig. 2). The test results of all cell culture solutions, we found that all the different cell lines could detect MMP13 except lung normal cell line (Table V). Interesting, MMP13 is indeed a secretion protein and it is highly expressed in breast cancer and colon cancer cell lines. At the same time, we utilized MMP13 antibody to perform IHC stain in the collected tissue biopsies of breast cancer patients, to investigate MMP13 expression in breast cancer tissues. The antibody used was the same as that in Western blot analysis. A positive 
yellowish-brown appearance after tissue dyeing indicated that MMP13 was $100 \%$ overexpressed in all breast cancer tissues (Fig. 3).

\section{Discussion}

In recent years, many studies have proven that early diagnosis is one of the most effective methods to lower the incidence and mortality of breast cancer. Compared to traditional cellular diagnosis or pathological dyes, the clinical test method of tumor markers is more convenient, simpler, less expensive and less invasive for early diagnosis of breast cancer. In addition, the public readily accepts it. However, the current tumor markers widely used in breast cancer screening all have their individual restrictions with the primary issue being low specificity and sensitivity (24). In this study, we selected four candidate markers the MMP13, CAMP, COL10A1, and TLJ25416 from the initial gene group presenting overexpression. Among these, evidence indicated that MMP13 was the most commonly overexpressed gene in the tumor tissue of clinical breast cancer patients (100\%). Therefore, MMP13 has tremendous potential to serve as a biological marker to assist in the clinical diagnosis of breast cancer.

The human MMPs family includes 24 members $(25,26)$. This protein family mainly functions as proteolytic enzymes, and they can dissolve extracellular matrix $(27,28)$. This family of proteins not only participates in normal physiological functions, such as wound healing and modulating growth factors and enzyme activation pathways (28-31), it also plays an important role in cancer infiltration, metastasis and angiogenesis (32-35). MMP13 (collagenase-3), MMP1 (collagenase-1) and MMP8 (collagenase-2) are all collagens. These three types of collagenase all have very high structural homogeneity. They can breakdown collagen types I, II, III, and V (31). Of these, MMP13 is most effective in breaking down type II collagen (36). Nielsen et al pointed out that in the process of breast cancer turning from ductal carcinoma in situ to invasive ductal carcinoma, MMP13 will break down basement membranes of tissues to form an invasive cancer (37). A consensual theory may be reached for this biochemical characteristic based on the results of this study, which demonstrate that MMP13 was only expressed in the highly invasive breast cancer cell line, MDA-MB-231, but not in the less invasive MLF-7 breast cancer cell line (38-40). This result also conforms to those gathered by Selvamurugan and Partridge (41).

In addition, many studies have discussed the relationship between MMP13 and other cancers. For example, MMP13 is overexpressed in colon cancer tissues $(42,43)$. In a head and neck squamous cell carcinoma study, MMP13 was found to be related to the invasiveness of cancer cells, and could be used to evaluate patient prognosis (44). This result was also confirmed in oral squamous cell carcinoma where MMP13 was determined to be a potential OSSC tumor marker (45). MMP13 increased its overexpression in tissues after metastasis in prostate cancer patients. Therefore, it can be a biomarker for prostate cancer diagnosis, treatment monitoring, and prognosis determination (46). Of note, although MMP8 and MMP1 have homogeneous structures,
MMP8 was postulated to play a protective role in a study related to lymph node metastasis (47). The age of onset of breast cancer patients in Taiwan is about 10 years earlier than patients in the Western nations, and in these young patients, the breast cancer is more invasive. Whether these differences relate to the expression of MMP13 and MMP8 in breast cancer tissues require further studies.

In the future, we will measure the MMP13 protein in the plasma of breast cancer patients and normal individuals, find the relationship between MMP13 concentration and clinical breast cancer symptoms, and clinically evaluate the sensitivity and specificity of MMP13 protein in breast cancer diagnosis. From results obtained in this study, we believe that MMP13 has the potential to become a new breast cancer tumor marker, when accompanied by current clinical screening methods, may increase the rate of early breast cancer diagnosis.

\section{Acknowledgements}

We would like to thank the patient and control subjects for their participation. This study was supported by grant NSC 95-2320-B-037-027 from the National Science Council of the Republic of China.

\section{References}

1. Groot MT, Baltussen R, Uyl-de Groot CA, et al: Costs and health effects of breast cancer interventions in epidemiologically different regions of Africa, North America, and Asia. Breast J 12 (Suppl. 1): S81-S90, 2006.

2. Jemal A, Siegel R, Ward E, et al: Cancer statistics, 2006. CA Cancer J Clin 56: 106-130, 2006.

3. 2005 Cancer Registry Annual Report, Department of Health, The Executive Yuan, Taiwan.

4. 2006 Health Statistics, Department of Health, The Executive Yuan, Taiwan.

5. Lo YL, Yu JC, Huang CS, et al: Allelic loss of the BRCA1 and BRCA2 genes and other regions on $17 \mathrm{q}$ and $13 \mathrm{q}$ in breast cancer among women from Taiwan (area of low incidence but early onset). Int J Cancer 79: 580-587, 1998.

6. 2004 Breast Cancer Staging Report, Department of Health, The Executive Yuan, Taiwan.

7. Taiwan Cooperative Oncology Group (TCOG), National Institute of Cancer Research, National Health Research Institutes: Common Consensus of Breast Cancer Diagnosis and Therapy, 1998.

8. Jemal A, Thomas A, Murray T and Thun M: Cancer statistics, 2002. CA Cancer J Clin 52: 23-47, 2002.

9. Alexander H, Stegner AL, Wagner-Mann C, et al: Proteomic analysis to identify breast cancer biomarkers in nipple aspirate fluid. Clin Cancer 10: 7500-7510, 2004.

10. Duffy MJ: Serum tumor markers in breast cancer: are they of clinical value? Clin Chem 52: 345-351, 2006.

11. Clinical practice guidelines for the use of tumor markers in breast and colorectal cancer. Adopted on May 17, 1996 by the American Society of Clinical Oncology. J Clin Oncol 14: 2843-2877, 1996

12. Bast RC Jr, Ravdin P, Hayes DF, et al: 2000 update of recommendations for the use of tumor markers in breast and colorectal cancer: clinical practice guidelines of the American Society of Clinical Oncology. J Clin Oncol 19: 1865-1878, 2001.

13. Chan DW, Beveridge RA, Muss H, et al: Use of Truquant BR radioimmunoassay for early detection of breast cancer recurrence in patients with stage II and stage III disease. J Clin Oncol 15: 2322-2328, 1997.

14. Chen Y, Zhang Y, Yin Y, et al: SPD - a web-based secreted protein database. Nucleic Acids Res 33 (Database issue): D169-D173, 2005.

15. Bendtsen JD, Nielsen H, von Heijne $G$ and Brunak S: Improved prediction of signal peptides: SignalP 3.0. J Mol Biol 340: 783-795, 2004. 
16. Guda C and Subramaniam S: pTARGET (corrected) a new method for predicting protein subcellular localization in eukaryotes. Bioinformatics 21: 3963-3969, 2005.

17. Janku F, Srovnal J, Korinkova G, et al: Molecular detection of disseminated breast cancer cells in the bone marrow of early breast cancer patients using quantitative RT PCR for CEA. Neoplasma 55: 317-322, 2008.

18. Chen CC, Hou MF, Wang JY, et al: Simultaneous detection of multiple mRNA markers CK19, CEA, c-Met, Her2/neu and hMAM with membrane array, an innovative technique with a great potential for breast cancer diagnosis. Cancer Lett 240: 279-288, 2006.

19. Sheu CC, Yu YP, Tsai JR, et al: Development of a membrane array-based multimarker assay for detection of circulating cancer cells in patients with non-small cell lung cancer. Int J Cancer 119: 1419-1426, 2006

20. Chen CC, Chang TW, Chen FM, et al: Combination of multiple mRNA markers (PTTG1, Survivin, UbcH10 and TK1) in the diagnosis of Taiwanese patients with breast cancer by membrane array. Oncology 70: 438-446, 2006.

21. Chang MY, Yu YP, Tsai JR, et al: Combined oligonucleotide microarray-bioinformatics and constructed membrane arrays to analyze the biological pathways in the carcinogenesis of human lung adenocarcinoma. Oncol Rep 18: 569-579, 2007.

22. Von Fournier D, Weber E, Hoeffken W, et al: Growth rate of 147 mammary carcinomas. Cancer 45: 2198-2207, 1980.

23. Freshney RI: Culture of Animal Cells. 3rd edition. John Wiley \& Sons, New York, 2000.

24. Li J, Zhang Z, Rosenzweig J, et al: Proteomics and bioinformatics approaches for identification of serum biomarkers to detect breast cancer. Clin Chem 48: 1296-1304, 2002.

25. Lafleur MA, Handsley MM and Edwards DR: Metalloproteinases and their inhibitors in angiogenesis. Expert Rev Mol Med 5: 1-39, 2003.

26. Ala-Aho R, Ahonen M, George SJ, et al: Targeted inhibition of human collagenase-3 (MMP-13) expression inhibits squamous cell carcinoma growth in vivo. Oncogene 23: 5111-5123, 2004.

27. Lafleur MA, Drew AF, de Sousa EL, et al: Upregulation of matrix metalloproteinases (MMPs) in breast cancer xenografts: a major induction of stromal MMP-13. Int J Cancer 114: 544-554, 2005.

28. Culhaci N, Metin K, Copcu E and Dikicioglu E: Elevated expression of MMP-13 and TIMP-1 in head and neck squamous cell carcinomas may reflect increased tumor invasiveness. BMC Cancer 4: 42, 2004.

29. Gearing AJ, Beckett P, Christodoulou M, et al: Processing of tumour necrosis factor-alpha precursor by metalloproteinases. Nature 370: 555-557, 1994.

30. Overall CM, McQuibban GA and Clark-Lewis I: Discovery of chemokine substrates for matrix metalloproteinases by exosite scanning: a new tool for degradomics. Biol Chem 383: 1059-1066, 2002.

31. Van den Steen PE, Proost P, Grillet B, et al: Cleavage of denatured natural collagen type II by neutrophil gelatinase B reveals enzyme specificity, post-translational modifications in the substrate, and the formation of remnant epitopes in rheumatoid arthritis. FASEB J 16: 379-389, 2002.
32. Curran S and Murray GI: Matrix metalloproteinases: molecular aspects of their roles in tumour invasion and metastasis. Eur J Cancer 36: 1621-1630, 2000.

33. Itoh Y and Nagase H: Matrix metalloproteinases in cancer. Essays Biochem 38: 21-36, 2002.

34. Yu AE, Hewitt RE, Connor EW and Stetler-Stevenson WG: Matrix metalloproteinases. Novel targets for directed cancer therapy. Drugs Aging 11: 229-244, 1997.

35. Lynch CC and Matrisian LM: Matrix metalloproteinases in tumor-host cell communication. Differentiation 70: 561-573, 2002.

36. Knauper V, Lopez-Otin C, Smith B, Knight G, and Murphy G: Biochemical characterization of human collagenase-3. J Biol Chem 271: 1544-1550, 1996.

37. Nielsen BS, Rank F, Lopez JM, et al: Collagenase-3 expression in breast myofibroblasts as a molecular marker of transition of ductal carcinoma in situ lesions to invasive ductal carcinomas. Cancer Res 61: 7091-7100, 2001.

38. Thompson EW, Paik S, Brunner N, et al: Association of increased basement membrane invasiveness with absence of estrogen receptor and expression of vimentin in human breast cancer cell lines. J Cell Physiol 150: 534-544, 1992.

39. Wang TN, Qian X, Granick MS, et al: Thrombospondin-1 (TSP-1) promotes the invasive properties of human breast cancer. J Surg Res 63: 39-43, 1996.

40. Giambernardi TA, Grant GM, Taylor GP, et al: Overview of matrix metalloproteinase expression in cultured human cells. Matrix Biol 16: 483-496, 1998.

41. Selvamurugan N and Partridge NC: Constitutive expression and regulation of collagenase- 3 in human breast cancer cells. Mol Cell Biol Res Commun 3: 218-223, 2000.

42. Mori D, Nakafusa Y, Miyazaki K and Tokunaga O: Differential expression of Janus kinase 3 (JAK3), matrix metalloproteinase 13 (MMP13), heat shock protein 60 (HSP60), and mouse double minute 2 (MDM2) in human colorectal cancer progression using human cancer cDNA microarrays. Pathol Res Pract 201: 777-789, 2005.

43. Roeb E, Arndt M, Jansen B, et al: Simultaneous determination of matrix metalloproteinase (MMP)-7, MMP-1, -3, and -13 gene expression by multiplex PCR in colorectal carcinomas. Int $\mathrm{J}$ Colorectal Dis 19: 518-524, 2004.

44. Luukkaa M, Vihinen P, Kronqvist P, et al: Association between high collagenase- 3 expression levels and poor prognosis in patients with head and neck cancer. Head Neck 28: 225-234, 2006.

45. Chiang WC, Wong YK, Lin SC, et al: Increase of MMP-13 expression in multi-stage oral carcinogenesis and epigallocatechin-3-gallate suppress MMP-13 expression. Oral Dis 12: 27-33, 2006.

46. Morgia G, Falsaperla M, Malaponte G, et al: Matrix metalloproteinases as diagnostic (MMP-13) and prognostic (MMP-2, MMP-9) markers of prostate cancer. Urol Res 33: 44-50, 2005.

47. Leivonen SK, Ala-Aho R, Koli K, et al: Activation of Smad signaling enhances collagenase-3 (MMP-13) expression and invasion of head and neck squamous carcinoma cells. Oncogene 25: 2588-2600, 2006. 